\title{
A SAÚDE COMO BEM HUMANO BÁSICO EM FINNIS
}

\author{
HEALTH AS A BASIC HUMAN GOOD IN FINNIS
}

JEAN CARLOS DIAS

Doutor em Direitos Fundamentais e Relações Sociais pela pela Universidade Federal do Pará (2006). Mestre em Instituições Jurídico-Políticas pela Universidade Federal do Pará (2002). Pós-graduado em Direito Civil e Processo Civil pela Unesa ? Rio de Janeiro (2000). Graduado em Direito pela Universidade Federal do Pará (1993), e Atualmente é Advogado, Sócio-Sênior de Bastos \& Dias s/s, escritório especializado em Direito Empresarial em Belém no Estado do Pará fundado em 1993. Professor de Teoria do Direito, Direito Processual Civil, Teoria Geral do Processo e Direito Econômico nos cursos de graduação e pós-graduação do Centro Universitário do Pará

\section{VERSALHES ENOS NUNES FERREIRA}

Mestre em Direito, Políticas Públicas e Desenvolvimento Regional pelo Centro Universitário do Estado do Pará (CESUPA). Especialista em Direito do Trabalho pela Universidade da Amazônia (UNAMAIntegrante do grupo de pesquisa "Trabalho Decente (CESUPA/CNPq) e da linha de pesquisa "Teorias da Justiça e Políticas Públicas: Fundamentação" (CESUPA/CNPq).

\section{RESUMO}

Objetivo: $O$ estudo objetiva compreender a lei natural e direitos naturais, baseado na aproximação entre direito e moral. Assim, objetiva perquirir sobre a teoria jusnaturalista de John Mitchell Finnis, a fim de aproximar o direito positivo e o direito natural com a condição basilar para o alcance do florescimento da sociedade e do próprio indivíduo.

Metodologia: Para atingir os fins esperados, a metodologia utilizada será documental, utilizando-se o método dedutivo, com caráter bibliográfico. Para tanto, utilizou-se a 
revisão bibliográfica, adotando-se como marco teórico John Finnis, especialmente por intermédio da obra "Lei Natural e Direitos Naturais".

Resultados: Com alicerce na teoria jusnaturalista de Finnis, o artigo aborda a pesquisa científica, na medida em que aproximou-se 0 direito positivo e o jusnaturalismo, bem como demonstra que a saúde é um bem jurídico fundamental. Assim, apresenta como resultado o pensamento de Finnis, ao revelar os critérios utilizados por ele para a construção de sua lista de bens, que reside na compreensão de que os valores listados são perceptíveis, óbvios, manifestos, inquestionáveis e não precisam de demonstração, pois são objetivos; a mera observação da vida em sociedade é capaz de os identificar. Seus bens são a própria razão de qualquer ação moral ou racionalmente moral, além de outros critérios valorativos de cunho universal que alcançam culturas, instituições, ações e requisitos morais, enfim, um plexo de bens que permitam à pessoa sua realização no contexto coletivo, sem, contudo, hierarquizá-los. Por fim, ao resgatar a teoria defendida por John Finnis, resgata-se, por conseguinte, a importância que a saúde merece, pois é um integrante do bem básico da vida.

Contribuições: A contribuição central do presente trabalho cinge-se em defender, argumentativamente, a possibilidade de entender a saúde como bem básico autônomo em Finnis, pois os bens básicos para ele têm um caráter pré-moral, prépolítico e pré-jurídico, ou seja, ainda não se transformaram em obrigações e, acreditase, sem a proteção do bem saúde seria praticamente impossível a uma sociedade alcançar o seu florescimento, que é propósito externado pelo filósofo em sua obra.

Palavras-chave: Saúde; John Finnis; jusnaturalismo; direito e moral.

\section{ABSTRACT}

Objective: The study aims to understand natural law and natural rights, based on the approximation between law and morality. It aims to investigate John Mitchell Finnis' s jusnaturalist theory in order to bring positive law and natural law closer to the basic condition for achieving the flourishing of society and the individual himself.

Methodology: To achieve the expected purpose the methodology used will be documentary, using the deductive method with bibliographic character. The bibliographic review was used adopting John Finnis as a theoretical framework, especially through the work "Natural Law and Natural Rights".

Results: Based on Finnis' s jusnaturalist theory, the article addresses scientific research as positive law and jusnaturalism approached, as well as demonstrating that health is a fundamental legal good. It presents Finnis's thinking as a result by revealing the criteria used by him for the construction of his list of goods, which lies in the understanding that the values listed are perceptible, obvious, manifest, unquestionable 
and do not need demonstration, as they are objective; the mere observation of life in society is capable of identifying them. Their assets are the very reason for any moral or rationally moral action, in addition to other universal valuation criteria that reach cultures, institutions, actions and moral requirements, in short, a plexus of assets that allow the person to perform it in the collective context, without, however, to rank them. Finally, when rescuing the theory defended by John Finnis, it is therefore rescued the importance that health deserves, as it is an integral part of the basic good of life.

Contributions: The central contribution of this paper is to defend, arguably, the possibility of understanding health as a basic autonomous asset in Finnis, since the basic goods for him have a pre-moral, pre-political and pre-legal character, that is, they have not yet become obligations and, it is believed, without the protection of good health it would be practically impossible for a society to achieve its flourishing, which is a purpose expressed by the philosopher in his work.

Keywords: Health; John Finnis; jusnaturalism; right and moral.

\section{INTRODUÇÃO}

Em 1980, a filosofia contemporânea do Direito ganhou um novo expoente em seu rol de pensadores, aonde repousam nomes como Ronald Dworkin, H.L.A. Hart, Joseph Raz, dentre outros, que buscaram investigar o Direito e explicá-lo a partir de diversas perspectivas - interpretativismo, positivismo inclusivista e exclusivista, realismo jurídico -, fala-se de John Mitchell Finnis e sua nova teoria jusnaturalista, sistematizada na obra Lei natural e direitos naturais, que representou uma revitalização para os estudos do direito natural.

A publicação de Lei natural e direitos naturais, base para as reflexões deste estudo, exteriorizou o ideário de Finnis, baseado na aproximação entre direito e moral, utilização de fundamentação racional vinculado à moral, distanciando-se de argumentos metafísicos, além da defesa da existência de bens básicos que somente uma instituição humana como o Direito poderia assegurá-los ou protegê-los, assim como, requisitos de razoabilidade prática que somente aquele poderia satisfazer. A associação entre direito positivo e direito natural como condição basilar para o alcance do florescimento da sociedade e do próprio indivíduo é ideia que merece atenção na teoria de Finnis, por representar uma mudança de direção na teoria do Direito. 
O aspecto central da presente análise cinge-se em defender, argumentativamente, a possibilidade de entender a saúde como bem básico autônomo em Finnis, considerando sua fundamentalidade para a existência do indivíduo e viabilizando a busca de seus projetos de vida, ou melhor, de seu próprio florescimento em consonância com o bem comum, além de enquadrar-se nos critérios empregados para a formação da lista originária de bens.

Ora, os bens básicos em Finnis possuem um caráter pré-moral, pré-político e pré-jurídico, ou seja, ainda não se transformaram em obrigações, e, acredita-se, sem a proteção do bem saúde seria praticamente impossível a uma sociedade alcançar o seu florescimento, propósito externalizado pelo filósofo em sua obra. Assim, o problema da pesquisa reside na possibilidade ou não de compreender a saúde como bem básico no sistema jurídico de John Finnis.

O artigo está dividido em duas partes. Inicialmente, realiza-se um breve apanhado com alguns dos principais pontos da teoria jusnaturalista de Finnis, assim como, estudam-se os bens básicos originais delimitados pelo referido autor, acrescendo o matrimônio, todos entendidos como formas para se alcançar o florescimento humano, ou seja, meios para a sociedade e as pessoas alcançarem sua potencialidade ou aprimoramento máximo. Por fim, a pesquisa defenderá a proposição de que a saúde é um bem básico a merecer autonomia na teoria de Finnis, não podendo continuar a funcionar como elemento apenso a outros bens básicos.

O presente ensaio é uma obra de hermenêutica, ancorada na análise qualitativa e, para atingir o objetivo elencado, a metodologia empregada foi a revisão bibliográfica de livros e artigos científicos sobre o tema, adotando-se como marco teórico John Finnis, especialmente por intermédio da obra Lei natural e direitos naturais.

\section{A TEORIA DA LEI NATURAL E OS BENS BÁSICOS EM FINNIS}

O anglo-australiano John Mitchell Finnis publicou Lei natural e direitos naturais em 1980, tornando-se, com o tempo, sua obra de maior prestígio, em 
decorrência de afirmar e defender a importância da razão na busca do florescimento humano, bem como, por conceber o direito natural alicerçado em uma filosofia prática que recorre a princípios de razoabilidade, o que colaborou para tornar-se o principal expoente do jusnaturalismo na contemporaneidade.

Finnis (2007) distribuiu suas ideias em 13 capítulos, dividindo-os em três momentos, alegando que a segunda parte (capítulos III a XII) concentrara as argumentações mais relevantes, pois, nela, poderiam ser encontradas discussões sobre ética filosófica, filosofia política e filosofia do direito, frisando que tais assuntos foram abordados de maneira entrelaçada. No prefácio, é dito que a obra deve ser considerada uma introdução, isso porque algumas questões relevantes não serão aprofundadas, algumas objeções não serão satisfatoriamente combatidas e não haverá esforço para expor uma cronologia das teorizações da lei natural e dos direitos naturais.

$\mathrm{Na}$ apresentação do texto, é frisado que Finnis procurou afastar-se de fundamentos metafísicos que sempre cercaram a temática a ser analisada, uma vez que, existe uma persistente desconfiança de que um teórico do direito natural é, por definição, um metafisico. Diz ele que nada será afirmado ou defendido por meio de um apelo à autoridade de qualquer pessoa ou grupo. Os princípios da lei natural, ou seja, os bens humanos básicos, serão apresentados como uma dimensão substancial (FINNIS, 2007).

Os propósitos de John Finnis com a publicação estão em mostrar que o jusnaturalismo ainda é uma teoria importante, que não foi ultrapassada, que não é obsoleta, assim como, revelar as características básicas desta corrente, asseverando que essa teoria tem respostas aos debates contemporâneos do Direito. Fez, em verdade, uma reconsideração do direito natural para os tempos atuais. $\mathrm{O}$ grande legado de Finnis, pelo que se depreende do texto, foi a aproximação entre direito e moral. Pensou a moral como um ponto de vista relevante para a construção do Direito, tendo a razoabilidade prática como o elo entre ambos. Em Finnis, a moral assumiu papel central, diferentemente da condição subalterna ocupada em Hart e Raz, por exemplo. 
A moral, em Finnis, é alçada à categoria de critério de validade das ações humanas, eis que a virtude do direito e de suas instituições reside, justamente, na produção da moralidade nas ações por intermédio da razoabilidade. Neste aspecto, os bens humanos básicos serão, em Finnis, os responsáveis por direcionar a ação das pessoas e serão os responsáveis pela travessia da prática à moral. Sobre a razoabilidade, Gardner (2012, on line, tradução livre) preleciona:

\begin{abstract}
Deixe-me abordar algumas possíveis objeções a esse modo de pensar sobre a justiça. Primeiro, como Finnis insiste, as únicas ações que exibem a virtude de seus agentes são ações justificadas ou ações (sinônimo) razoáveis. Ao contrário dos ensinamentos exóticos de alguns "eticistas da virtude", as ações não são razoáveis porque são virtuosas. Pelo contrário: as ações são virtuosas porque são razoáveis. ${ }^{1}$
\end{abstract}

Finnis (2007) criou as bases para uma nova teoria do direito natural, defendendo que a fonte deste direito repousa, primeiramente, nos dinamismos experienciados de nossa própria natureza e, pari passu, nos princípios inteligíveis que delineiam os aspectos do florescimento humano, ou seja, nos valores básicos que foram apreendidos pelo entendimento humano. O que, por desdobramento, o fez rejeitar, assim, fatores instintivos e emocionais, inserindo o florescimento da sociedade como o objetivo precípuo do direito natural. Em suas linhas, buscou assentar que a validade jurídica de uma norma depende de um feixe de qualidades substancialmente morais.

Neste aspecto, ao tratar, especificamente, da lei natural, constatou-se que o fundamento desta se concentra em princípios de cunho racionais (inteligibilidade) que acabam por orientar as ações humanas na direção de bens ou finalidades (diretividade) mais elementares buscadas por si mesmas, as quais desempenham um papel fundacional no raciocínio prático e na ação humana racional (MIRANDA, 2016). Acrescente-se a isso o fato de que o jusnaturalismo, marcado por seu caráter

\footnotetext{
${ }^{1}$ No original: "Let me address a couple of possible objections to this way of thinking about justice. First, as Finnis rightly insists, the only actions that exhibit the virtue of their agents are justified actions or (synonymously) reasonable actions. Contrary to the exotic teachings of some 'virtue ethicists', however, actions are not reasonable because they are virtuous. On the contrary: actions are virtuous because they are reasonable" (GARDNER, 2012, on line).
} 
universal, imutável e natural, tem, por conta disso, um grande desafio, qual seja, responder aos anseios de uma sociedade multicultural, complexa e plural.

O jusnaturalismo de princípios racionais, capaz de conferir inteligibilidade e diretividade às ações humanas, aonde é possível localizar o sistema de Finnis, deslocou o seu centro de estudo, o seu campo de investigação da natureza para o homem, distanciando-se das ideias de divino e cósmico. E, a racionalidade do indivíduo tornou-se o fundamento de tudo. Finnis afastou o obscurantismo religioso e supersticioso que estigmatizavam o direito natural, e tornava-o mal compreendido (PINHEIRO \& SOUZA, 2016b). A sua reconsideração ao direito natural, acima referida, pode ser confirmada em afirmações que o próprio autor realiza.

Diz Finnis (2007) que existem bens humanos básicos que só podem ser assegurados através de instituições humanas, como as leis, ou seja, o autor não combate o positivismo, não o torna adversário do jusnaturalista, tampouco oferta olhar hostil à essa corrente do direito. Ou seja, coisas boas para a existência humana, tais como, uma sociedade ordeira, livre da tirania ou de opressão, pessoas usufruindo felicidade, dentre outros exemplos, só podem ser garantidas, asseguradas, através da existência da lei.

Por outro lado, Bix (2002) acentua que as incorporações, pela teoria da lei natural, de uma avaliação moral ou de outros aspectos da moralidade, podem tornar esta teoria superior a uma teoria positivista legal, porque estaria mais completa e rica, eis que incluiria ou refletiria aspectos de nossa prática e experiência cotidianas. Neste aspecto, o direito natural será o critério para avaliar, julgar, comparar e hierarquizar o direito positivo.

Finnis (2007) aduz que existem exigências de raciocínio prático que apenas instituições ou leis humanas podem satisfazer, e define as demandas do raciocínio prático como um conjunto de fundamentos, demandas metódicas que definem o pensamento correto do incorreto e oferece um critério para diferenciar entre atos que são razoáveis e atos que não são razoáveis. De modo que, à primeira vista, o raciocínio prático indica o uso da razão, o senso comum para encontrar formas de ação. 
Percebe-se, logo no início, que o objetivo de Finnis não era formular uma nova teoria jurídica, mas, sim, progredir sobre os pressupostos filosóficos de uma forma clássica de se conceber o Direito. Sua influência adveio de filósofos a exemplo de Aristóteles - quando trabalhou com a ideia de meio-termo, equilíbrio, felicidade -, Tomás de Aquino - ao estudar a virtude como nascida da natureza humana -, além de Clarke e Hume, quando estudaram noções de ser e dever-ser (FINNIS, 2007). E não apenas esses, Finnis também chamou ao diálogo Bentham, Austin, Kelsen, Hart, Hohfeld, Fuller.

O autor explicita sua intenção de descrever os fundamentos de um direito natural revigorado, novo, contemporâneo, elencando bases e fundamentos argumentativos racionais vinculados à moral e afastando-se de argumentos de autoridade, superstições, justificativas metafísicas. Finnis (2007) afirma que usufruir dos sete bens básicos do ser humano depende da razoabilidade prática que se posiciona em cada opção realizada e, das escolhas feitas, sendo que esta liga-se à moralidade, o que ele exemplifica quando responde à pergunta sobre como saberemos que uma decisão é razoável na prática. Para o filósofo, apenas o ser dotado de experiência, inteligência e um desejo pela razoabilidade mais forte do que os outros desejos poderá oferecer uma resposta à essa indagação.

Possuir um plano coerente de vida, não ter preferência arbitrária por pessoas ou valores, desprendimento, compromisso, bom senso, bem comum e respeito a estas diretrizes permitirá a existência da razoabilidade prática nas opções do indivíduo. À vista disso, a decisão razoável terá em sua estrutura profunda a moral, eis que requisitos da razoabilidade prática geram uma linguagem moral, discernida por um escorço de reflexão. Ao trabalhar com a razoabilidade prática, Finnis (2007, p. 25) descreve-a dizendo:

Razoabilidade prática é razoabilidade na decisão, na adoção de compromissos, na escolha e na execução de projetos e, em geral, na ação. A filosofia prática é uma reflexão disciplinada e crítica sobre os bens que podem ser realizados na ação humana e nos requisitos da razoabilidade prática. Então, quando dizemos que o teórico descritivo (cujos propósitos não são práticos) deve agir, em sua seleção e formação indispensável de conceitos, adotando um ponto de vista prático, queremos dizer que ele deve avaliar a importância ou o alcance das semelhanças e diferenças em seu 
assunto perguntando o que seria considerado importante ou significativo nesse campo por aqueles cujas preocupações, decisões e atividades criam ou constituem o assunto.

Deste modo, a razão prática em Finnis é o bem pelo qual as pessoas buscam as outras formas de bens humanos básicos. Todos esses bens são considerados objetivos, eis que se a racionalidade prática é subjetiva, então, todos terão sua própria interpretação do que é bom ou ruim. O filósofo (Finnis, 2007) fala que todos devem seguir sua consciência. Evidentemente, o que Adolf Hitler praticou durante o tempo em que esteve no poder, pode, para este ditador, ser praticamente razoável ou sua consciência o incitou a fazê-lo, e se seguirmos à risca a teoria de Finnis, Hitler não fez nada de errado ao, simplesmente, seguir sua consciência. Por isso, é bom atentar para a subjetividade da razoabilidade prática, visto que todo mundo tem um motivo diferente para adotar esta ou aquela atitude.

Deste modo, é através da razoabilidade prática que as pessoas poderão buscar os outros bens básicos para seu próprio florescimento, sendo que todos são livres para escolherem quais os bens que pretendem perseguir e quais, por consequências, serão ignorados no decorrer da vida. Como a razoabilidade prática também é um bem básico, acaba que esta, em Finnis, pode ser visualizada como um meio e como um fim.

A escolha por alguns dos bens básicos, a partir de critérios racionais, denota sua moralidade justamente por serem tais critérios razoáveis e visando o bem comum. Logo, o fundamento do Direito seria tanto racional quanto moral, por passar por uma série de questionamentos do ser quando posto no caso concreto existente no cotidiano. A função precípua do legislador é perceber a existência dessa racionalidade e dessa moralidade para estabelecer a norma, não tendo, assim, tanta liberdade quando de sua escolha (FINNIS, 2007).

Considerando que a lei é criada a partir de critérios, racionais e morais, a pessoa é impelida, naturalmente, a cumprí-la, não sendo as normas subordinadas por argumentos teológicos. E, tal dever é indispensável para que o bem comum seja alcançado e haja justiça no seio social. Do contrário, em existindo lei que agrida a razoabilidade prática - interpretada como a racionalidade e moralidade, surgirá 
conflito entre as bases da lei e a ela própria, motivando as pessoas ao seu descumprimento dada a falta de razoabilidade prática de tal regra.

John Finnis é filósofo de singular relevância para o novo jusnaturalismo, em especial por estruturar seu ideário no fato do homem ser racional e, por isso, procurar definir suas ações práticas numa razoabilidade que irá ter aderência a condutas morais, visto que direcionadas ao bem comum e à não lesão de outrem. É como se Finnis condicionasse a convivência social justa ao exercício efetivo da racionalidade pelas pessoas (PINHEIRO \& SOUZA, 2016a).

Frente à contemporaneidade e complexidade do mundo atual, seu pensamento ganha substrato quando confere aos direitos naturais as mesmas características atribuídas a eles pelos pensadores clássicos, porém, transferindo o fundamento para a razão, característica eminentemente humana e distante da metafísica. O ideário de Finnis deixou claro que para a teoria jusnaturalista, o Direito só conseguirá atingir suas finalidades quando estiver devidamente conectado com a moral. O Direito depende de uma instância externa a ele, vai depender da moral em algum grau, pois, para os jusnaturalistas, o Direito não é autossuficiente.

Assim, tomando por base o pressuposto de que o jusnaturalismo é uma teoria normativa do direito, ou seja, está preocupada com o debate sobre o valor fundamental do direito, e mais, determinando referido valor com base em argumentações acerca do bem, e, com isso, ofertando uma visão de como o direito deveria ser, e não de como o direito é, como o faz o positivismo, Finnis (2007) buscou descrever esta instituição social a partir de seus melhores exemplos, eis que, segundo ele, só assim veremos o Direito alcançar suas finalidades. Utilizou a estratégia denominada de casos centrais.

Os casos centrais representam as ordens jurídicas mais bem-sucedidas, as ordens jurídicas que alcançaram a finalidade do Direito, ordens que representam o bom funcionamento da instituição social Direito. Finnis, então, buscou encontrar esses exemplares mais bem-sucedidos - chamados de casos centrais -, em seguida, extraiu as características que os fizeram alcançar suas finalidades - significado focal -, para chegar ao chamado ponto de vista apropriado. Este é o ponto de vista do indivíduo, 
isto é, ponto de vista de quem está esperando do Direito a orientação prática moralmente aceitável.

Orientação prática significa dizer o que pode ser considerado justificado ou não no modo de agir humano. Para Finnis (2007), o ponto de vista apropriado está na convergência entre o que a orientação prática do Direito determina e minhas crenças e finalidades morais. Assim, chega ao ponto central em que a finalidade do Direito é oferecer uma orientação prática moralmente aceitável. As pessoas querem e precisam de uma orientação, desde que seja moralmente aceitável.

Finnis (2007) nos diz que o Direito é moralmente aceitável quando fornece uma orientação prática capaz de possibilitar o florescimento humano. Florescimento humano que pode ser associado à felicidade, à realização de uma vida humana plena satisfatória. Evidentemente, inexiste uma fórmula para dizer quando a vida humana é bem realizada e bem-sucedida. Posto que, existem várias, inúmeras formas, visto que cada pessoa tem o seu próprio projeto de vida. Cada pessoa pode buscar sua própria forma de florescimento, desde que sua escolha não frustre o projeto de vida das demais, se o fizer, será considerado ilegítimo.

Quando Finnis analisa as formas de florescimento humano, fixa o entendimento de que existem certas coisas que são basilares para o ser humano conseguir seu aprimoramento e, com isso, desenvolver seu potencial crescimento, refere-se aos bens humanos básicos, que, como valores para a existência humana constituem-se em substrato valorativo do homem em todos os seus juízos morais, e, ainda que não sejam compreendidos e realizados com igual intensidade, não deixam de serem universais e fundamentais (SGARBI, 2007). A partir daí, exsurge a necessidade de assegurar e proteger tais bens básicos.

Sgarbi (2007) afirma que os bens básicos em Finnis são conhecidos por todo ser humano bastando que façam uso da razão ou da experiência, sendo que tais princípios, tais valores somente podem ser assegurados ou protegidos mediante instituições humanas, tal como o Direito que, para Finnis, constitui-se em exercício de poder e exercício de racionalidade, funcionando como vetor a estatuir o que é ou não devido positivamente, assim como, favorecendo o bem-comum, tratando os sujeitos com igual consideração, conduzindo a atuação dos funcionários da ordem jurídica 
para evitar abuso de autoridade e respeitando os ditames da justiça distributiva. Deste modo, a realização dos bens básicos congregará a realização do bem comum e favorecerá cada indivíduo a desenvolver as formas básicas em sua esfera na comunidade.

O próprio Finnis (1994) aduz que a realização humana integral pode e deve ser uma concepção central para uma teoria da lei natural da moralidade e, portanto, da própria política. Deste modo, se o Direito consegue auxiliar no florescimento da sociedade e das pessoas, então, ele é moralmente aceitável. É por isso que Finnis (2008, on line, tradução livre) afirma que: "O direito positivo, em suma, acrescenta muito conteúdo aos princípios e padrões de razoabilidade prática tradicionalmente chamados de lei natural".2

E, a busca desse florescimento deve passar, como dito outrora, necessariamente, pela realização de bens humanos básicos. Esses bens, quando combinados e hierarquizados no âmbito subjetivo, permitem alcançar esse potencial máximo. O florescimento humano consiste na realização, combinação e hierarquização de um certo número de bens considerados indispensáveis à vida digna. Bens que são valiosos em si mesmos, são fins em si mesmos. Em outros termos, são valores básicos para a própria existência humana constituindo-se em substrato valorativo da pessoa em todos os seus juízos morais (DIAS, 2015). Antecedem, assim, o moral, o político e o jurídico, sendo universais e fundamentais aos indivíduos.

Finnis (2007), ao cuidar da fundamentalidade desses bens, aduz que é evidente que cada um deles é uma forma de bem, nenhum pode ser considerado analiticamente reduzido a um mero aspecto de qualquer um dos outros ou ser tido como instrumental para a busca de qualquer um dos outros, bem como, quando a pessoa se concentra em um desses bens, este pode ser encarado de modo razoável como o mais importante. Afirma inexistir qualquer hierarquia objetiva entre eles, posto que todos são igualmente fundamentais e indispensáveis ao florescimento. E mais,

\footnotetext{
2 No original: "Positive law, in short, adds much content to the principles and standards of practical reasonableness traditionally called natural law" (FINNIS, 2008, on line).
} 
diz que eles só podem ser garantidos por meio das instituições do direito humano e requisitos de razoabilidade prática a que apenas essas instituições podem satisfazer.

Esses bens representam os princípios que devem ser utilizados para valorar um juízo moral, em outros termos, representam critérios de julgamento, de valoração para as ações, para os juízos morais. Se relacionam ao conceito de florescimento humano, entendido como a busca pela realização das potencialidades humanas, guiada pela racionalidade prática que deverá desenvolver meios de facilitação para essa realização. Para Finnis (2007), é através dos bens básicos que o homem alcançará seu florescimento, alcançará ou atingirá seu potencial máximo. Sem esses bens, sem esses elementos, a realização do pleno potencial dos seres humanos não é possível. Sobre os bens básicos elucida West (2011, on line, tradução livre):

\begin{abstract}
Esses produtos básicos, argumenta Finnis, não são conhecidos por nós através da antropologia ou da sociologia, mas sim pela nossa capacidade de raciocínio prático - embora recebam um forte impulso das evidências emprestadas das ciências sociais. (...) Conhecemos o conteúdo desses bens individuais, básicos e intrínsecos individualmente, por meio da reflexão, temperada e informada pela experiência ${ }^{3}$.
\end{abstract}

Finnis (2007) acredita que essas formas básicas do bem humano são anteriores à moral, são elementos essenciais para a realização do próprio homem, formando um verdadeiro arcabouço para a proteção e garantia da dignidade da pessoa. Elenca sete bens básicos em sua obra de 1980, quais sejam: vida, conhecimento, jogo, experiência estética, sociabilidade, religião e razoabilidade prática. Mais tarde, por intermédio de um artigo intitulado "Commensuration and public reason", incluiu o casamento, realizando uma reformulação à proposta original (FINNIS, 2011a). Vejamos, a partir de agora, os bens básicos em Finnis.

Inicia-se pelo bem do Conhecimento. $\mathrm{O}$ autor fala da busca de conhecimento pelo próprio conhecimento. É o conhecimento da verdade, perseguido pelo puro desejo de saber, de encontrar a verdade sobre qualquer matéria, em qualquer campo

\footnotetext{
${ }^{3}$ No original: "These basic goods, Finnis argues, are not known to us through anthropology or sociology but rather through our capacity for practical reason - althrough given a hefty boost from evidence borrowed from the social sciences. (...) We come to know the content of these individual, basic, intrinsic goods individually, through reflection, tempered and informed by experience" (WEST, 2011, on line).
} 
do saber humano, simplesmente no que diz respeito à verdade e ao desejo de evitar o erro ou a ignorância. É através desse conhecimento que "apreendemos os valores básicos da existência humana e assim, também, os princípios básicos de todo raciocínio prático" (FINNIS, 2007, p. 67).

Assevera que o conhecimento é o "fundamento avaliador de todos os juízos morais" (FINNIS, 2007, p. 67), revelando-se como a atividade de descobrir, de compreender, de julgar de maneira correta as coisas. O cerne da questão neste bem básico é a busca, é se lançar à investigação, ao exame, à averiguação, à pesquisa. É a curiosidade como combustível do perseguir. Deve-se perseguir o conhecimento para afastar-se da ignorância. O bem básico do conhecimento é auto-evidente, não podendo ser empiricamente provado ou comprovado, e deve ser entendido como valor em si mesmo, não podendo ser utilizado como instrumental.

Como diz Finnis (2007), o conhecimento é algo que é bom ter, pois, é melhor ser bem informado e lúcido a ser confuso e ignorante. Logo, vale a pena procurar a verdade, somente através dela, conquistada por intermédio do conhecimento, se poderá alcançar a plenitude máxima defendida pelo filósofo.

O Jogo é outro bem básico disposto por Finnis. Este bem se traduz no conjunto de atividades que são prazerosas e recompensatórias em si mesmas, independentemente de outras finalidades. É o se engajar em atividades sociais que não têm qualquer propósito senão o seu próprio exercício. Como diz Finnis (2007), o desempenho deste bem pode ser solitário ou social, físico ou intelectual, tenso ou relaxado, convencional ou de padrão ad hoc.

A Experiência estética também figura na lista do filósofo. Relaciona-se com algum grau ou alguma forma de prazer estético, ou, então, uma estimulação de prazer sensorial. Pode ser traduzida com o belo artístico, o belo natural, a própria contemplação da natureza, a dança, a música. Finnis (2007, p. 93) diz: "A experiência estética, diferentemente do jogo, não precisa envolver ação de nossa parte; o que é buscado e valorizado por si mesmo pode ser simplesmente a forma bela 'exterior' à pessoa, e a experiência 'interior' da apreciação de sua beleza”.

Mais uma forma de bem é a Sociabilidade. É o bem da convivência com os outros, simbolizando o não estar sozinho. Não estar sozinho dentro daquela 
experiência, daquele contexto. Este é o nível mínimo. Por outro lado, ter uma amizade plenamente realizada, querer o bem do outro, realizar o bem na família, no ambiente profissional, este pode ser entendido como o nível máximo (FINNIS, 2007).

Este componente do florescimento humano é realizado com um mínimo de paz e harmonia entre as pessoas e se estende desde as formas da comunidade humana até a forma mais consistente no florescimento da plena amizade. O bem da amizade inclui ações realizadas em favor dos propósitos de um amigo, para o bemestar do amigo, por conta disso, pode-se entender a sociabilidade ou amizade como uma ferramenta essencial para se alcançar o bem comum, visto que, quando uma pessoa se dedica em benefício de outrem, além de colaborar ou coordenar de maneira recíproca, advém um bem comum fruto de uma verdadeira autorrealização. Sobre o bem comum, Finnis (2007, p. 155) esclarece que é:

(...) um conjunto de condições que permita que os membros de uma comunidade atinjam, por si mesmos, objetivos razoáveis ou que realizem de modo razoável, por si mesmos, o valor em nome do qual eles têm razão de colaborar uns com os outros (positiva ou negativamente) em uma comunidade.

Deste modo, pode-se entender o bem comum como aquilo que é bom para todos ao mesmo tempo. Como os bens básicos são bons para todos ao mesmo tempo, logo, são bens comuns. Traduz-se o bem comum quando uma instituição como o Direito possibilita e favorece o florescimento de todos os indivíduos, isto é, o florescimento da sociedade. E fará isso possibilitando o acesso aos bens básicos, através, por exemplo, quando o Estado protege e favorece a vida, ele está favorecendo o florescimento do bem da vida para todos. Quando o Estado prevê punições e penas, ele está viabilizando o bem comum.

A razoabilidade prática possibilita o florescimento de todos. Um sistema educacional, previdenciário, favorecem o florescimento de todos ao mesmo tempo. E, quando esse mesmo Estado investe em seu sistema público de saúde, também está favorecendo o florescimento do bem da vida, e viabilizando o bem-estar de seus habitantes. Portanto, pensar em bem comum é pensar na criação de condições para realização do florescimento da sociedade. 
Razoabilidade prática é outra forma de bem básico. Pode ser compreendida como a capacidade que o indivíduo tem de planejar, a médio e longo prazo, um plano de vida que, para ele, é relevante. Acaba por representar modos de se atingir cada um ou todos os bens básicos listados por Finnis. Este bem exerce influência nas ações das pessoas, auxiliando na definição dos caminhos a serem seguidos.

O agir moral no contexto de perseguir um bem humano básico é uma imposição da razoabilidade prática. Com ela, o indivíduo poderá determinar se uma decisão é ou não razoável. Pode, ainda, ser entendida como condição para que o ser humano delibere com sabedoria acerca de determinado tema, fazendo a coisa certa no momento certo. Funcionando como orientação na atividade de delimitar os caminhos que serão seguidos pelas pessoas, Finnis (2007, p. 105) diz sobre a razoabilidade prática o seguinte:

\begin{abstract}
Ao revelar um horizonte de possibilidades atraentes para nós, nossa apreensão dos valores básicos cria, assim, em vez de responder, o problema da decisão inteligente: o que deve ser feito? $O$ que pode ficar sem ser feito? O que não deve ser feito? Não temos, teoricamente, nenhuma razão para deixar qualquer um dos bens básicos de fora. Mas temos, realmente, boas razoes para escolher compromissos, projetos e ações sabendo que uma escolha efetivamente elimina muitos compromissos, projetos e ações alternativos razoáveis ou possíveis.
\end{abstract}

Saber agir e saber viver em busca do florescimento humano é um tanto complexo, pois, implica liberdade e razão, por isso, a razoabilidade prática é um valor complexo. Contudo, este mesmo valor complexo faz com que a própria inteligência seja aplicada, efetivamente, aos problemas de escolher as ações e o estilo de vida de cada um e de formar o próprio caráter, essenciais à construção de um ser apto à conquista de sua própria plenitude.

A Religião também é um bem básico. $O$ autor não entende esse valor como sendo algum tipo de instituição eclesiástica, mas, como um princípio de compatibilização das condutas individuais com uma ordem geral além de cada um. Essa ordem não precisa de uma crença, mas, do reconhecimento de que deve existir um estado de coisas em que mesmo um ateu pode limitar o arbítrio humano. Wallin (2012, on line, tradução livre) complementa: 
O bem básico da religião engloba o reconhecimento de uma preocupação por "uma forma de ordem irredutivelmente distinta". Esse bem aborda o senso individual de responsabilidade de uma pessoa ao escolher o que ele é para ser e fazer e a percepção de que esse sentido não pode ser reduzido aos conceitos abordados pelos outros bens básicos ${ }^{4}$.

Em termos práticos, a religião enquanto bem humano básico refere-se à relação que existe entre uma pessoa e uma divindade qualquer. Isso porque, caso Finnis vinculasse sua lei natural e os princípios da razoabilidade prática, como subordinadas a uma vontade de Deus, sua teoria se dissociaria do seu objetivo de justamente buscar uma legitimação por critérios objetivos e não metafísicos. O bem religião deve ser determinado por cada um de nós e o Estado, como instituição, não deve impedir que as pessoas exerçam, livremente, sua religião.

Mais recentemente, Finnis incluiu o matrimônio ou casamento como bem básico. Ao trabalhar com este bem humano básico, entendido, pelo autor, como um instituto representativo da união de duas pessoas de sexos diferentes com o objetivo de constituição de família e sobrevivência da espécie, complementa dizendo (FINNIS, 2008, on line, tradução livre):

\begin{abstract}
O matrimônio é um bem humano fundamental distinto porque permite que as partes, marido e mulher, prosperem como indivíduos e como casal, tanto pela forma mais irreal possível de união entre os seres humanos quanto pela mais radical e criativa capacitação de seres humanos, auxiliando a outra pessoa a florescer, inclusive, trazendo outra pessoa à existência como conceptus, embrião, criança e, eventualmente, adulto plenamente capaz de participar do florescimento humano sob sua própria responsabilidade. ${ }^{5}$
\end{abstract}

Por fim, far-se-á referência à Vida. A vida, em Finnis, vai desde a sobrevivência física, ou seja, a possibilidade de vida biológica até a máxima realização

\footnotetext{
${ }^{4}$ No original: "The basic good of religion encompasses the recognition of a concern for "an irreducibly distinct form of order". This good addresses a person's individual sense of responsibility in choosing what he is to be and do and the realization that this sense cannot be reduced to the concepts addressed by the other basic goods" (WALLIN, 2012, on line).

${ }^{5}$ No original: "Marriage is a distinct fundamental human good because it enables the parties to it, the wife and husband, to flourish as individuals and as a couple, both by the most farreaching form of togetherness possible for human beings and by the most radical and creative enabling of another person to flourish, namely, the bringing of that person into existence as conceptus, embryo, child and eventually adult fully able to participate in human flourishing on his or her own responsibility. (...) " (FINNIS, 2008, on line).
} 
de uma vida plenamente vivida. O autor toma o termo vida como qualquer aspecto da vitalidade que coloca um ser humano em um ótimo caminho para a autodeterminação. Dentro desse conceito, a vida engloba o estado físico e mental, a saúde, a liberação da dor, enfim, viabiliza à pessoa buscar, efetivamente, seu florescimento.

A qualidade do bem humano vida também corresponde à tendência de preservação e propagação da espécie humana, motivo pelo qual a vida deve ser protegida contra qualquer ataque que a coloque em risco, aonde surge a importância do Estado em afastar qualquer ação que ofereça potencial temeridade à sua manutenção.

Esta é a lista de bens fundamentais para a humanidade segundo o intelecto de John Finnis, sendo que esta lista não é exaustiva, pois, além desses valores, existem inúmeros objetivos e formas de bem. Sendo que, esses outros objetivos e formas de bem, ao serem analisados, são modos ou combinações de realizar uma das formas básicas desses bens. Todavia, e é bom frisar, mais importante do que o número preciso e a descrição desses valores é em que sentido cada um é básico.

Em primeiro lugar, é igualmente evidente por si mesmo que cada um é uma forma de bem. Em segundo, nenhum pode ser analiticamente reduzido a meramente um aspecto de qualquer um dos outros, nem ser instrumental para a busca de qualquer dos outros. Em terceiro lugar, cada um, quando nos concentramos nele, pode ser encarado de modo razoável como o mais importante. Portanto, não existe qualquer hierarquia objetiva entre eles, todos são essenciais ao florescimento humano.

A concepção de Finnis sobre seus bens básicos repousa na ideia de que existem valores relativos a todos os seres humanos, em qualquer tempo e em qualquer lugar que estejam; os bens listados refletem ou refletiriam uma preocupação entre todas as sociedades do globo, pois, todas elas exteriorizam preocupações com a vida, o conhecimento, a amizade, o jogo, a religião, a experiência estética e a razoabilidade prática. Finnis (2007, p. 89), deste modo, destaca: 
motivo apropriado para a ação, e em nenhuma delas o homicídio é permitido sem alguma justificativa bem definida. Todas as sociedades humanas encaram a procriação de uma nova vida humana como, em si mesma, uma boa coisa, a menos que existam circunstâncias especiais. Nenhuma sociedade humana deixa de restringir a atividade sexual; em todas as sociedades existe alguma forma de proibição de incesto, algum tipo de oposição à promiscuidade ilimitada e ao estupro, alguma preferência por estabilidade e permanência nas relações sexuais. Todas as sociedades humanas demonstram preocupação com a verdade por meio da educação dos jovens em questões não apenas práticas (e.g. evitação do perigo), como também especulativas ou teóricas (e.g. religião). Os serem humanos, que só sobrevivem à infância quando são bem cuidados, vivem em sociedade, ou às margens de alguma sociedade que invariavelmente se estende para além da família nuclear, e todas as sociedades demonstram favorecer os valores de cooperação, do bem comum acima do bem individual, da obrigação entre os indivíduos e da justiça dentro dos grupos. Todos conhecem a amizade. Todas têm alguma concepção de meum e tuum, direito à propriedade ou patrimônio, e de reciprocidade. Todos valorizam o jogo, sério e formalizado, ou informal e recreativo. Todos tratam o corpo dos membros mortos do grupo de algum modo tradicional e ritual que é diferente do modo como descartam o lixo. Todas demonstram interesse por poderes ou princípios que devem ser respeitados por seres sobre-humanos; de uma forma ou de outra, a religião é universal.

Finnis, através desta passagem, deixa clara sua posição quanto à universalidade dos seus bens básicos, eis que todos estão interligados ao potencial humano de crescimento, que seria um objetivo universal, e, ainda que as pessoas não os compreendam ou não consigam alcançar sua realização em intensidade máxima, eles são universais e servem de vetor para todas as pessoas no decorrer de suas vidas.

\section{A SAÚDE COMO BEM BÁSICO EM FINNIS}

A saúde é um bem essencial para a existência humana e para a prática de atos em sociedade, qualificando-se como direito humano de todas as pessoas, necessária à preservação da dignidade individual. É ela capaz de proporcionar o pleno bem-estar físico, mental e social das pessoas, garantindo-Ihes plena participação social, auxiliando-as na realização de seus planos de vida e possibilitando um viver digno. 
Esse verdadeiro estado da vida é fundamental para o desenvolvimento pessoal e a segurança econômica dos indivíduos, sem ela, inexiste base para a produtividade, para o aprendizado e para o crescimento intelectual, físico e emocional. A qualidade da saúde do indivíduo é um dos aspectos primordiais para o combate à desigualdade social, sendo dever precípuo do Estado, através de seus representantes, implementar, ampliar e consolidar os direitos humanos, entre os quais, a saúde, revelando-se este ato estatal como orientação prática moralmente aceitável.

A importância desta condição basilar individual é tamanha que o direito internacional previu sua proteção em diversos instrumentos. A Declaração Universal dos Direitos Humanos de 1948 consagrou, através de seu artigo XXV, 1, o direito à saúde, dispondo, in verbis: "Todo ser humano tem direito a um padrão de vida capaz de assegurar a si e a sua família, saúde e bem-estar, inclusive [...] cuidados médicos e os serviços sociais indispensáveis [...]" (FERREIRA FILHO, 2016, p. 212). Além dela, tem-se o Pacto Internacional sobre os Direitos Econômicos, Sociais e Culturais de 1966, a Convenção Americana sobre Direitos Humanos de 1969 e o Protocolo Adicional à Convenção Americana sobre Direitos Humanos em Matéria de Direitos Econômicos, Sociais e Culturais de 1988.

A saúde é um verdadeiro pressuposto para o regular exercício das liberdades e para a promoção da igualdade, sendo que por meio dela é que se torna possível dar curso às ações necessárias para o cumprimento dos objetivos de vida de cada indivíduo, revelando-se, deste modo, como instrumento de concretização da dignidade da pessoa humana. Eis que, não há como falar em dignidade sem um direito à saúde efetivado, enfim, sem o direito de participar da vida em sociedade com um mínimo de condições. Sem a oferta satisfatória da saúde pelo Estado, comprometidos estarão o crescimento, o desenvolvimento econômico do país e a redução da pobreza, eis que ela é um dos principais insumos para se alcançar esses objetivos.

$E$, é justamente o caráter de fundamentalidade do bem saúde que o faz merecedor de valoração para antes mesmo de positivação em leis, visto que sua importância decorre da própria natureza, é algo bom a todos os seres humanos e é evidente por si mesma. A relevância da saúde não precisa ser demonstrada, decorre 
da natureza das coisas, de sua própria essencialidade aos indivíduos na busca de seu florescimento. A integridade da saúde individual simboliza a própria integridade do ser humano, e, por desdobramento, a integridade de sua dignidade, qualidade intrínseca e distintiva de todas as pessoas, viabilizando, assim, o exercício de sua liberdade.

Tomando nossa ordem jurídica vigente como parâmetro, a saúde é prevista em normas legais, sendo que a autoridade, referenciada em Finnis (2007), previu e regulou este bem, para que a comunidade pudesse perseguir seus propósitos em comum, in casu, o bem comum, além de contribuir para que o próprio indivíduo alcance sua potencialidade. Aqui, vê-se a importância da autoridade, legitimada pelo direito escrito, tendo em vista o bem comum. Em Finnis, é a consecução do bem comum que justifica a existência da autoridade.

Ademais, a valoração da saúde como bem essencial em si é encontrada não apenas em nossa sociedade, como em outras sociedades e em outras épocas, eis que possibilita um campo de oportunidade para todos os indivíduos, viabilizando práticas humanas que levam a pessoa a atingir seu florescimento em sociedade. Por conta disso, é um tipo de bem humano básico, por isso, constitutivo e intrínseco ao ser racional.

Ora, a saúde reveste-se como um aspecto do bem-estar humano que é bom não apenas para si, como para qualquer outra pessoa, contribuindo para que a sociedade alcance seu próprio florescimento - pretensão exteriorizada por Finnis na construção de seu sistema jurídico, desdobrando-se ou contribuindo para que todos obtenham um completo bem-estar, podendo ser compreendida como bem humano fundamental por permitir que todos os indivíduos prosperem, não no sentido econômico, não era este o propósito precípuo de Finnis, mas, no sentido de permitir o florescimento das capacidades naturais do homem.

Além disso, a saúde também auxilia na construção de uma cidadania livre, na formação de novos cidadãos, independentes e responsáveis, por isso é um bem importante e insubstituível, pois, quando usufruído com racionalidade, leva a pessoa a percorrer caminhos auspiciosos, adotando uma trajetória que leva à realização individual, e, por consequência, ao florescimento coletivo. Todavia, na teoria normativa do direito de Finnis a saúde é tratada como bem humano vinculado ao bem 
básico da vida, não possuindo, por isso, independência. Data venia, discorda-se desta configuração, pois, a saúde é um bem de salutar importância para o exercício da liberdade individual plena, sem a qual, fica impossibilitado de buscar suas metas de vida.

Finnis (2011b) defende que o bem da vida permanece, especificamente, humano 6 e próprio à pessoa, inclusive, englobando a saúde, ainda que essa vida seja ou não inerentemente boa ou mesmo quando não se possa mais desfrutar de algum grau de função afetiva cognitiva ou quando não se possa mais alcançar outros valores. Em outras palavras, para Finnis, o bem básico da vida permanece intacto, valorativamente falando, ainda que a pessoa esteja em coma, em estado vegetativo, enfim, desprovida de saúde e autonomia, pois, em seu pensamento, com ou sem saúde, a vida corporal humana deve prevalecer, motivo pelo qual, a saúde sempre estará englobada na vida, não alcançando, em Finnis, autossuficiência.

Pois bem. A teoria de John Finnis objetivou apresentar fundamentos para a valoração do Direito, partindo esta valoração de uma discussão sobre bens básicos valiosos ao indivíduo, ainda no campo da pré-moralidade, mais que terão sua origem, justamente, em um Direito com traços qualitativos. E, neste aspecto, o florescimento por intermédio dos bens básicos, que possuem valor em si mesmos, exigirá uma atuação estatal positiva, para proteger referidos bens, eis que é a realização desses bens que permitirá à sociedade florescer.

${ }^{6}$ Convém abrir parêntese para uma questão. Ao tratar da razoabilidade prática que, para Finnis,
representa justamente os modos de se atingir cada um de seus bens básicos, trazendo, assim,
elementos com os quais possamos responder se determinada decisão é razoável ou não, advém a
questão das escolhas a serem realizadas pelos seres humanos em seu cotidiano, e que devem balizar-
se pela realização do bem no mundo, tanto em sua própria vida, como na vida das outras pessoas, e
que acabam por adentrar no cerne da moralidade. Ora, inúmeros são os contextos em que as pessoas
deverão, com razoabilidade, calcular, medir, comparar, pesar e avaliar as consequências de suas
decisões alternativas. E, no campo das escolhas que deverão ser feitas, Finnis (2007) diz que é
razoável preferir o bem humano ao bem dos animais, onde uma escolha deve ser feita, é razoável
preferir bens humanos básicos (como a vida) a bens meramente instrumentais (tal como o direito à
propriedade). Onde o dano é inevitável, é razoável preferir atordoar a ferir, ferir a aleijar, aleijar a matar.
Todavia, e aí reside a inquietação, é possível uma sociedade florescer ofertando, pari passu, tratamento
cruel a animais irracionais, ou seja, é possível uma sociedade alcançar sua potencialidade máxima,
moralmente falando, dispensando tratamento excruciante à sua fauna e à sua flora, isto é, às outras
formas de vida, ou, simplesmente, desconsiderando sua existência? É possível à sociedade atingir o
florescimento ignorando outros espécimes? 
A questão é pensar em florescimento de uma sociedade sem ofertar à saúde um lugar de destaque. É moralmente razoável pensar a saúde como elemento merecedor de independência na teoria de Finnis, notoriamente por revelar-se uma necessidade humana, sem a qual, prejudicado estará o florescimento de qualquer sociedade. A saúde é um valor inquestionável e irrefutável, pois, sem saúde, o florescimento humano não seria possível, a atualização das potências fundamentais dos indivíduos seria impensável. Não se consegue vislumbrar florescimento de uma coletividade sem lançar luzes ao valor saúde.

Portanto, data venia, é filosoficamente interessante e importante pensar a saúde como bem humano fundamental autônomo. Sua essencialidade ao ser humano e ao florescimento da própria sociedade, com o alcance do bem comum, possibilita levantar esta hipótese na medida em que a ausência de saúde inviabiliza a busca de outros bens básicos, impedindo a pessoa de alcançar sua potencialidade máxima e impossibilitando-a de contribuir com o bem coletivo, mesmo sendo detentora de razão.

Finnis desenvolveu sua teoria a partir do debate sobre os bens humanos básicos, reservando à saúde um papel secundário, acessório ao bem da vida, o que não se coaduna com seu propósito de listar bens fundamentais para a humanidade capazes de viabilizar o florescimento social e, por consequência, o florescimento individual. Por óbvio, o florescimento não se dá da mesma maneira para todos, eis que a liberdade permite a adoção de planos de vida distintos, no entanto, essa realização depende de determinados bens básicos, que serão mais ou menos enfatizados, conforme as diferentes decisões das pessoas.

E, quaisquer que sejam os objetivos de vida de uma pessoa ou os objetivos de uma sociedade, não se consegue imaginar sua realização sem existir a saúde como bem ou como fim elementar a ser buscado e realizado pela ação humana racional. A supracitada assertiva decorre do entendimento de que os bens humanos básicos são, além de fundamentos racionais que sustentam toda ação e pensamento prático, também explicam de maneira racional a ação humana e toda a organização social, política e jurídica dos seres humanos (MIRANDA, 2016). Motivações estas que também advogam em prol da tese de que é necessária a inclusão da saúde no rol de 
bens em Finnis, colaborando, assim, no favorecimento de cada indivíduo a desenvolver as formas básicas em sua esfera na comunidade.

Entende-se que a saúde é um bem essencial à humanidade, não podendo ser estudada como mero acessório do bem da vida em Finnis, como elemento complementar deste ou daquele bem, ela é essencial aos seres humanos, e, vê-la sob a perspectiva de sua natural e singular autonomia é privilegiar a dignidade humana. $A$ saúde é um valor fundante de uma sociedade que pretende florescer, ela é um valor universal, logo, pode derivar para o campo obrigacional e, sucessivamente, para o campo jurídico. Erigi-la à categoria de bem básico acarreta, como implicação, considerando o filtro da razoabilidade prática, o fato de que se torna um bem a ser buscado e realizado na ação como desdobramento da inteligência humana, não acarretando maiores consequências ao bem da vida, que continuará a funcionar como forma de florescimento humano, englobando a busca pela preservação da própria vida, a perpetuação da espécie, dentre outras acepções.

Ao concluir esta exposição que defende a inclusão da saúde como bem básico autônomo na teoria de Finnis, considerando sua fundamentalidade e subsunção aos critérios utilizados por Finnis para a descrição de seus bens básicos pré-morais, este ensaio justifica a sua hipótese fundamental de análise, qual seja, ofertar autonomia ao valor da saúde, pois, é impossível pensar numa sociedade que floresce sem proteger o bem básico da saúde.

\section{CONCLUSÃO}

A saúde é uma questão que tem ocupado, ao longo dos anos, o centro das atenções de diversas pessoas, governos, comunidades e empresas, sendo que a sociedade espera que o setor da saúde funcione e, com isso, cuide das pessoas e das populações, seja com ações individuais, seja com ações coletivas. Sua importância é indiscutível, pois, trata-se de direito humano.

Nesse sentido, no presente artigo, buscou-se demonstrar que a saúde é um bem jurídico fundamental que merece ou merecia espaço autônomo no sistema 
jurídico de Finnis, e não apenas lugar subalterno no bem básico da vida. A saúde é de significativa relevância ao completo bem-estar das pessoas tanto que fora prevista em diversos instrumentos internacionais de proteção aos direitos humanos, inclusive, nossa própria Constituição a definiu como direito fundamental dos cidadãos e dever do Estado.

Em sua obra Lei natural e direitos naturais, Finnis (2007) deixou claro que na construção de sua teoria não iria se valer de questões metafísicas para legitimar seu ideário, para tanto, utilizou específicos critérios na formulação e catalogação de seus bens humanos básicos, prelecionando, de início, que os considera autoevidentes e imprescindíveis ao florescimento da sociedade. Ou seja, um dos critérios utilizados para a construção de sua lista de bens reside na compreensão de que os valores listados são perceptíveis, óbvios, manifestos, inquestionáveis, não precisam de demonstração, pois, são objetivos, sendo que a mera observação da vida em sociedade é capaz de os identificar. Seus bens são a própria razão de qualquer ação moral ou racionalmente moral.

Outro critério que se abstrai de sua obra, quanto aos bens básicos, é que sua formulação levou em conta o que se poderia pensar como valores práticos relativos à todas as pessoas, à todas as comunidades, na medida em que todos os seres humanos, no pensar de Finnis, preocupam-se com a vida, com o conhecimento, com o jogo, com a amizade, com a experiência estética, com a razoabilidade prática e com a religião. Ou seja, pensou na universalidade de valores, que alcançam culturas, instituições, ações, requisitos morais, enfim, um plexo de bens que permitam à pessoa sua realização no contexto coletivo, sem, contudo, hierarquizá-los.

Deste modo, convém frisar que Finnis utilizou, basicamente, dois critérios para elencar seus bens fundamentais: a autoevidência e imprescindibilidade de alguns bens necessários para se alcançar o florescimento, assim como, valores práticos universais que jamais seriam inobservados por qualquer pessoa, em qualquer lugar, visto que configuram-se como critérios de julgamento para qualquer ação que se espere seja imbuída de moralidade.

Neste sentido, tomando por base tais critérios, é possível defender a saúde como elemento apto a constar na lista de bens básicos de Finnis, posto que ela é um 
bem fundamental indiscutivelmente auto-evidente e essencial para que qualquer sociedade alcance seu potencial máximo, alcance seu florescimento, bem como, é um valor universal observado e perseguido por todos os seres humanos, bastando atentar os tratados internacionais que protegem este direito essencial, o que demonstra sua fundamentalidade para a comunidade internacional, o que desemboca numa verdade indubitável, qual seja, a saúde é um bem imprescindível para todos os seres humanos, sem a qual, sua própria dignidade resta ameaçada.

John Finnis não é um autor de conotação individualista, tanto que, em nosso sentir, é possível vislumbrar que sua lista é marcada por forte pressentimento ou intuição moral sobre bens essenciais para que uma sociedade possa florescer, a pretensão é mesmo universalista. Ocorre que, o apelo à universalidade e sociedade também podem ser pontos discutíveis, pois, é como se o autor não abrisse espaço para considerações, justamente, a respeito de individualidades, ou melhor, é como se desconsiderasse o pluralismo e propósitos marcadamente individuais.

O mundo é constituído de distintas culturas que apresentam manifestações peculiares, particulares, em razão de preferências, motivações e avaliações. A saúde, exatamente por ser usufruída no campo estritamente individual, pode ter ficado em zona de penumbra na construção de Finnis por este motivo, destarte, pelo fato de poder ser utilizada em uma avaliação de juízo moral, merecia espaço na lista de bens do filósofo jusnaturalista.

Ora, no campo pré-moral, a saúde, objeto deste estudo, pode ser considerada elemento fundamental para que sociedades desenvolvam sua potencialidade máxima e, com isso, por desdobramento, os indivíduos também venham a alcançar seu potencial superior. Seu destaque advém por seu caráter de fundamentalidade para todos os atos da vida em sociedade.

Por outro lado, conforme defende John Finnis, é razoável que a saúde seja integrante do bem básico da vida, todavia, em nosso sentir, é insuficiente que ela seja uma agregação ao bem da vida; sua fundamentalidade à sociedade que objetiva florescer e subsunção aos critérios utilizados para a criação da lista original, referendam a proposição defendida de que a saúde merece autonomia no sistema jurídico de Finnis. 
Inclusive, o próprio Finnis acrescentou o casamento como bem básico, já referenciado linhas pretéritas, denotando que sua lista original de 1980 não é inflexível, não é exaustiva, e comporta a inclusão de outros bens pré-morais, funcionais para uma sociedade que pretende florescer, derivando para o campo obrigacional e, em sequência, para o campo jurídico, visto que transfigura-se como valor universal.

Como se pôde observar, no primeiro momento o estudo ocupou-se com alguns pontos centrais do livro Lei natural e direitos naturais de Finnis e com seus bens básicos, acrescendo o casamento, inserido, posteriormente, nos escritos do autor. Por fim, defendeu-se a possibilidade de inserir a saúde como bem humano básico autônomo no sistema jurídico de Finnis, considerando que este valor essencial encontra sintonia com os critérios utilizados por Finnis para catalogar seus bens humanos básicos.

Por conseguinte, após as singelas análises de outrora, chega-se à conclusão que a saúde pode ser compreendida como bem autônomo na teoria de John Finnis, notadamente, pelo fato de que este valor se enquadra nos critérios utilizados pelo filósofo para a formação original de sua lista de bens básicos, assim como, revestirse de indubitável fundamentalidade, essencial ao florescimento da sociedade e, por desdobramento, ao florescimento dos indivíduos. A saúde é um direito natural, é um bem pré-moral, é universal e configura-se como valor fundante para se atingir o florescimento das sociedades.

\section{REFERÊNCIAS}

BIX, Brian, Natural Law Theory: The Modern Tradition. OXFORD HANDBOOK OF JURISPRUDENCE AND PHILOSOPHY OF LAW, Jules L. Coleman \& Scott Shapiro, eds., Oxford University Press, 2002. Available at SSRN: https://ssrn.com/abstract=199928 or http://dx.doi.org/10.2139/ssrn.199928. Acesso em: 07 jul. 2018.

DIAS, Jean Carlos. O direito natural no pensamento jurídico contemporâneo: John Finnis. In: DIAS, Jean Carlos (Coord.). O pensamento jurídico contemporâneo. Rio de Janeiro: Forense; São Paulo: MÉTODO, 2015, p. 137 - 152. 
FERREIRA FILHO, Manoel Gonçalves. Direitos humanos fundamentais. 15. ed. São Paulo: Saraiva, 2016.

FINNIS, John. Liberalism and Natural Law Theory, 45 Mercer L. Rev. 687 (1994). HeinOnline.

https://heinonline.org/HOL/Page?handle=hein.journals/mercer45\&collection=journals \&id=699\&startid=699\&endid=716. Acesso em: 13 jul. 2018.

FINNIS, John. Lei natural e direitos naturais. Tradução: Leila Mendes. Porto Alegre: Editora Unisinos, 2007.

FINNIS, John. Marriage: A Basic and Exigent Good (2008). The Monist, Vol. 91, pp. 388-406, 2008; Notre Dame Legal Studies Paper №. 09-13. Available at SSRN: https://ssrn.com/abstract=1392288. Acesso em: 10 jul. 2018.

FINNIS, John. Reason in action. Oxford: Oxford University Press, 2011a.

FINNIS, John. Economics, justice, and value of life. In: FINNIS, John. Human rights and common good. Collected Essays: Volume III. Oxford University Press, 2011 (2011b), p. 242-250.

GARDNER, John. Finnis on Justice (June 11, 2012). John Keown and Robert George (eds), Reason, Morality, and the Law: The Jurisprudence of John Finnis (Oxford: Oxford University Press 2012); Oxford Legal Studies Research Paper No. 29/2012. Available at SSRN: https://ssrn.com/abstract=2081900. Acesso em: 07 jul. 2018.

MIRANDA, John Florindo de. O insight prático no jusnaturalismo de John Finnis: uma tese sobre a aquisição dos fundamentos da moral. Kínesis - Revista de Estudos dos Pós-Graduandos em Filosofia, Vol. VIII, no 18, Dezembro 2016, p. 181-196. Disponível em: http://www2.marilia.unesp.br/revistas/index.php/kinesis/article/view/7705/0. Acesso em: 22 ago. 2018.

PINHEIRO, Victor Sales; SOUZA, Elden Borges. O laicismo e a teoria da lei natural em Finnis: a religião como bem humano básico. Arquivo Jurídico. ISSN 2317918X. Teresina (PI), v. 3, n 1, Jan./Jun. 2016 (2016a), p. 2 - 22. Disponível em: www.ojs.ufpi.br/index.php/raj/article/view/5702. Acesso em: 20 jul. 2018.

PINHEIRO, Victor Sales; SOUZA, Elden Borges. A fundamentação ética dos direitos humanos em John Finnis. Revista Direitos Humanos e Democracia, [S.I.], v. 4, n. 7, p. 65-83, ago. 2016 (2016b). ISSN 2317-5389. Disponível em: https://www.revistas.unijui.edu.br/index.php/direitoshumanosedemocracia/article/vie w/5513. doi: https://doi.org/10.21527/2317-5389.2016.7.65-83. Acesso em: 04 jul. 2018. 
SGARBI, Adrian. O direito natural revigorado de John Mitchell Finnis. Revista da Faculdade de Direito da Universidade de São Paulo. v. 102, jan./dez. 2007, p. 661689. Disponível em: http://www.revistas.usp.br/rfdusp/article/view/67774/70382. Acesso em: 22 ago. 2018.

WALLIN, Alex E. John Finnis's Natural Law Theory and a Critique of the Incommensurable Nature of Basic Goods. Campbell Law Review vol. 35, no 1 (Fall 2012): $\quad$ p. 59-82. HeinOnline, https://heinonline.org/HOL/P?h=hein.journals/camplr35\&i=67. Acesso em: 11 jul. 2018. 